\title{
EL RELATIVISMO AXIOLÓGICO CIENTÍFICO EN ARNOLD BRECHT: UN PUNTO DE PARTIDA PARA ABORDAR LA PROBLEMÁTICA ACTUAL
}

\author{
Isabel RUIZ-GALLARDÓN \\ Universidad Rey Juan Carlos de Madrid \\ ruiz.gallardon@terra.es
}

\section{TESIS FUNDAMENTALES DE LAS DOCTRINAS RELATIVISTAS EN EL SIGLO XX}

Los logros de la ciencia moderna y de sus métodos son indiscutibles. Sin embargo, parecen habernos vacunado contra la religión, la filosofía e incluso la ética, pues no han sido capaces de ofrecer medios contundentes para diferenciar el bien del mal, lo correcto de lo incorrecto, la justicia de la injusticia. Esto ha tenido una especial repercusión en el campo de la ciencia política, que todavía busca argumentos científicos para demostrar la objetividad de determinados valores como la democracia.

El relativismo científico aplicado a las ciencias sociales se basa en la afirmación de que ningún método científico ha podido determinar la superioridad de ningún fin o propósito sobre otro en términos absolutos. Sólo podemos confirmar su superioridad relativa como medios para conseguir ulteriores fines o propósitos, pero saber cuáles de estos últimos fines son superiores se escapa al análisis científico. Saber científicamente si el hombre tiene una dignidad que siempre debe ser respetada nos sitúa frente a problemas como el aborto, la eutanasia o la pena de muerte; saber si son más importantes los fines del individuo o del grupo y de qué individuos y qué grupos nos enfrenta a problemas como los derechos de las minorías o los límites legítimos de la expropiación y de la propiedad; saber si es más valiosa siempre la paz que la guerra nos enfrenta a problemas como la legitimidad de la guerra; saber si siempre debe primar la caridad sobre el egoísmo nos sitúa frente a los problemas derivados del libre mercado, la obligación de ayuda a los países más necesitados o la determinación de los impuestos.

Uno de los factores que más ha contribuido al relativismo en la filosofía legal y política es la doctrina que sostiene que no puede derivarse con- 
clusión lógica alguna —inductiva o deductivamente- de ninguna afirmación realizada en el ámbito del ser, respecto a un postulado del ámbito del deber ser. El origen de esta doctrina puede situarse en Kant, se extendió por toda la cultura occidental a través de filósofos alemanes como Wilhelm Windelband y Heinrich Rickert, y de ahí a los relativistas del mundo contemporáneo ${ }^{1}$.

A los argumentos que señalan los relativistas a favor de una estricta separación entre los reinos del ser y del deber ser pueden hacérseles dos objeciones no en relación a su separación lógica, sino a la importancia real de esta separación frente a otros elementos que establecen un firme puente entre ambos reinos. La primera objeción se basa en el hecho de que la naturaleza misma establece límites externos para la realización de objetivos últimos que podamos proponernos, así como en lo adecuado de los medios que se proponen para conseguirlos. Lo que es imposible hacer o realizar, como, por ejemplo, trabajar de forma ininterrumpida sin comida y sin descanso, puede eliminarse de manera científicamente concluyente de los objetivos que el hombre debe conseguir en la vida moral, legal o política, si realmente se prueba dicha imposibilidad. Demostrar esta imposibilidad real corresponde a la discusión científica, y en base a ella, la ciencia excluirá muchos objetivos propuestos por no poderse alcanzar, así como muchos medios por no ajustarse a los fines que se persiguen. Este tipo de investigación científica también se extiende a la determinación de los males implícitos en los objetivos que se proponen.

La segunda objeción que podemos hacer a la tesis que separa radicalmente los ámbitos del ser y del deber ser se basa en el hecho de que en la propia naturaleza humana existen elementos de deber ser tan enraizados que el pensamiento y el sentimiento humanos no pueden escapar a ellos. Muchos filósofos han intentado en el último siglo determinar cuáles son estos elementos invariables no sólo en nuestro pensamiento, sino también en nuestro sentir y en nuestra voluntad. Algunos se han conformado con establecer postulados de carácter meramente formal sin reclamar validez absoluta para las conclusiones derivadas de los requerimientos esenciales. Estos filósofos centran su interés en encontrar una definición correcta de la justicia e incluso, en ocasiones, van más allá y reclaman la validez universal e invariable de los estándares formales. Otros han intentado derivar princi-

${ }^{1}$ Para un análisis exhaustivo de estos autores vid. A. BRECHT, «Relative and Absolute Justice», Social Political Research, vol. 6 (febrero de 1939), pp. 58-87, y «The Rise of Relativism in Political and Legal Philosophy», Social Political Research, vol. 6 (septiembre de 1939), pp. 392-414. 
pios últimos estableciendo evidencias comparativas en los significados que pueda tener la justicia en diferentes países y tiempos más que a través de introspecciones subjetivas ${ }^{2}$.

Con todo, parece que encontrar postulados absolutos en la vida política y jurídica es bastante complicado cuando se intenta transmitir dichos postulados a través de pruebas científicas. Pero sí podemos establecer algunos criterios para hallar dichos elementos invariables, como, por ejemplo, los que están presentes en el postulado de justicia; estos criterios son: la experiencia inmediata de la evidencia, la confesión general de todo el mundo, la imposibilidad de imaginar un punto de vista que no contuviera dichos elementos y la imposibilidad de todo el mundo de imaginar lo anterior $^{3}$. Muy pocos relativistas serios niegan que ciertos fines y propósitos podrian ser superiores o incluso que pueda haber una verdad absoluta en la superioridad o inferioridad de los valores y que algunos puedan ver esta verdad correctamente y otros no puedan. Tampoco niegan que un hombre pueda tener una intuición sobre las diferencias básicas existentes en el valor de los fines y propósitos, y que dicha intuición se presente ante él con absoluta certeza de forma que constituya parte de su saber. Estos relativistas reconocen, pues, que puede existir una intuición válida sobre los valores, pero niegan que podamos comunicar a otros nuestras convicciones, saber o intuición sobre valores de forma que sea científicamente demostrable. En otras palabras: hay que distinguir entre convicciones, conocimiento e intuiciones subjetivas sobre la validez de los juicios de valor y la prueba intersubjetiva de dichos valores que pueda transmitirse de hombre a hombre a través de datos conclusivos asequibles también a otros.

Siendo ésta la tesis fundamental de los relativistas, la mayoría de ellos insiste en que los juicios de valor —especialmente los referentes a la ética- son afirmaciones sobre el sentido y no sobre hechos, sobre lo que debe ser y no sobre lo que es. Con todo, y esto es importante, tampoco niegan que la afirmación de que algo debe hacerse, o la preferencia emocional de que algo se haga o incluso el propósito de hacerlo, puedan basarse en un influjo trascendental; sólo afirman que éste no puede demostrarse de manera intersubjetivamente concluyente. Algunos han enfatizado que un influjo tal, si existiera, sería un hecho perteneciente al campo del ser imposible de ser demostrado científicamente.

2 Para conocer más sobre estos filósofos vid. M. Werthlermer, «Some Problems in the Theory of Ethics», Social Political Research, vol. 2 (1935), pp. 353-367, esp. p. 364.

3 Vid. A. BRECHT, «The Search for Absolutes in Political and Legal Philosophy», Social Political Research, vol. 7 (1940), p. 210. 


\section{EL SER Y EL DEBER SER}

Considerando la seriedad de los argumentos alegados por los relativistas y siendo nuestro propósito desmontarlos en parte, comenzamos por hacernos la siguiente pregunta: ¿puede probarse intersubjetivamente la superioridad o inferioridad de propósitos y fines, por ejemplo, en asuntos políticos? A pesar del escepticismo en lo concerniente a la demostración de los valores, los relativistas no niegan que la ciencia pueda contribuir a la discusión, clarificando el sentido preciso de las posibles interpretaciones y examinando las consecuencias de las acciones políticas basadas en dichas interpretaciones ${ }^{4}$.

A finales del siglo Xix los teóricos de la Ley Natural en la filosofía política y jurídica evolucionaron en sus conceptos sobre el deber ser en relación con lo que de hecho es. Hasta entonces, la línea argumentativa se desarrollaba de la siguiente manera: los seres humanos son, consecuentemente deben ser; nacen iguales, consecuentemente deben ser tratados como iguales; tienen un impulso natural a preservar la vida, consecuentemente deben tener el derecho de autodefensa; la sociedad existe y es útil para preservar la vida y la autodefensa, consecuentemente debe haber una sociedad. La oposición a una ley natural fundada en una lógica tal alcanzó su máxima expresión en la primera mitad del siglo xx y se basaba —como ya hemos comentado - en que ningún postulado del reino del deber ser puede derivarse lógicamente del una realidad del reino del ser. El hecho de que existan seres humanos no justifica que deban existir; tampoco el hecho de que exista la sociedad y una relación de interdependencia entre sus miembros prueba que debamos realizarnos en la sociedad o que la sociedad sea éticamente deseable. De esta forma — dirán los relativistasresulta sencillo verificar proposiciones del mundo físico o biológico del ser, pero establecer una prueba transmisible o comunicable sobre proposiciones del ámbito del deber ser, fundada en derivaciones lógicas apriorísticas sobre hechos tomados como meras falacias del mundo del ser, parece tarea imposible.

La doctrina de separación lógica entre los reinos del ser y del deber ser se ha combinado con la tesis de que ni siquiera los valores morales constituyen un puente entre ambos reinos. Esta tesis mantiene que los valores no existen como hechos en el ámbito del ser a pesar de que las interpretacio-

${ }^{4}$ A. Brecht, «Beyond Relativism in Political Theory», American Political Science Review, vol. XLI, núm. 3 (junio de 1947). 
nes que se hace de ellos sean cuestiones de hecho; es decir, mientras que los valores como tales no existen, cualidades consideradas valiosas como la generosidad o la honradez sí existen. Cualquier cosa puede demostrarse valorativamente en el sentido de que es útil como medio para obtener determinados fines, pero esto no prueba el valor incondicional de los medios a no ser que se demuestre también el valor incondicional del fin. Los valores éticos pertenecen al reino del deber ser por lo que sólo tendrá valor ético lo que debe ser, hacerse o probarse.

Así pues, desde el punto de vista de la lógica formal, las conclusiones que se deducen de la forma deber ser no pueden obtenerse únicamente de premisas de la forma del ser, sino de dos premisas, una de las cuales también tiene forma de deber ser. Por ejemplo, todos los seres humanos deberían tener derecho a la vida, Pedro es un ser humano, luego Pedro debería tener derecho a la vida.

Esta metodología de separación ha influido grandemente en la filosofía política y jurídica del siglo XX, si bien es cierto que a partir de la Segunda Guerra Mundial comenzó a iniciarse un camino de encuentro entre los reinos del ser y del deber ser que en el siglo XXI comienza a dar sus frutos, tal y como puede demostrarse en el análisis de acontecimientos recientes justificativos de la desobediencia civil como los sucedidos en la Primavera Árabe. Sin embargo, todavía se impone la doctrina de la separación entre ambos ámbitos, manteniéndose, así, pujantes las tesis del relativismo científico.

Quienes investigan sobre el posible nexo de unión entre el ser y el deber ser toman como principal punto de partida los procesos internos por los que de una forma natural o biológica perteneciente al ámbito del ser (una voz interior) nos dirigimos o sentimos apremiados por un deber ser ético. Esta «VOz interior» puede ordenarnos ser buenos o revelarnos una serie de valores jerarquizados que nos hará poner, por ejemplo, las acciones generosas por encima de las egoístas; de esta forma un deber ser ético se anunciaría a través de un ser. El vínculo entre ambos campos no tendría un carácter lógico, pero sí un carácter fáctico que, siendo tan evidente como es y pudiéndose probar intersubjetivamente, haría perder importancia a la doctrina que se basa tan sólo en la separación lógica. Bastaría con observar en el suficiente número de casos individuales este vínculo fáctico para extraer inductivamente la conclusión de su presencia universal con la misma seguridad o inseguridad que cualquier otra conclusión inductiva ${ }^{5}$. En definiti-

5 Vid. A. BRECHT, «The Myth of Is and Ought», Harvard Law Review, vol. 54, núm. 5, Cambridge, Massachussets, marzo de 1941, pp. 817 y ss. 
va, las deducciones lógicas del reino del deber ser presuponen, efectivamente, premisas en este mismo ámbito. Sin embargo, la lógica formal no es siempre una buena guía; de hecho, las conclusiones más absurdas pueden derivarse de premisas absurdas de una manera lógicamente correcta. $\mathrm{Y}$ es que el valor de una deducción formal depende principalmente de la veracidad de las premisas. El hecho de que las premisas sean verdad no se debe a razones lógicas, sino de concordancia con los hechos; llegar a una conclusión lógica desde una afirmación verdadera es sólo un problema secundario que se ha puesto, incorrectamente, en primer lugar. Podemos, entonces, decir que las afirmaciones verdaderas no son, en primer lugar, deducciones lógicas, ni tampoco su justificación se basa, en primer lugar, en conclusiones inductivas. Descansan, sobre todo, en la evidencia inmediata que sostiene la verdad de la afirmación o de sus elementos. Así pues, se trata de una afirmación fáctica y no una inferencia lógica cuando decimos que ciertos requerimientos específicos del deber ser forman parte de nuestra naturaleza humana. Estos requerimientos, este deber ser, sea cual sea su validez y su valor, es un hecho, un dato que encontramos en el ámbito del ser. Se trata, pues, de un puente entre los reinos del ser y del deber ser.

\section{LA PRUEBA INTERSUBJETIVAMENTE TRANSMISIBLE DE LOS VALORES}

Teniendo en cuenta lo anterior, la segunda pregunta que nos hacemos es la siguiente: ¿qué hay que entender por prueba intersubjetivamente transmisible? Francis G. Wilson, de la Universidad de Illionis, en la mesa redonda sobre el Relativismo en la Teoría Política que tuvo lugar en Ohio en $1946^{6}$, expuso que el análisis de la prueba puede realizarse desde dentro y desde fuera. Desde fuera, el valor de una propuesta política puede atacarse científicamente si se prueba que dicha propuesta es de realización imposible, que es imposible conseguir de manera alguna los objetivos propuestos, o que no se conocen los medios para conseguirlos, o que no se pueden conseguir con los medios que se proponen. Por ejemplo, se puede demos-

${ }^{6}$ F. G. WILSON, presidente de la mesa redonda Beyond Relativism in Political Theory, Cleverland (Ohio), diciembre de 1946. Esta mesa redonda tuvo lugar en la American Political Science Association y en ella participaron investigadores de teoría política de diferentes universidad de Estados Unidos. En estas páginas se recogen algunas de sus conclusiones examinadas por A. BRECHT en su artículo «Beyond Relativism in Political Theory», op. cit., pp. 470 y ss. 
trar científicamente que es imposible garantizar que un dictador a quien se ha dado todos los poderes hará siempre buen uso de ellos; que aunque tenga hoy buena voluntad la tendrá también en los próximos años, al igual que sus sucesores; que una vez que se le ha dado todo el poder se le pueda quitar sin su consentimiento si no es a través de una revolución; que es imposible que un dictador, aunque tenga buena voluntad, pueda supervisar personalmente el trato justo a todos los ciudadanos y que sin instituciones independiente o libertad de opinión pública se pueda controlar a sus delegados en quienes ha depositado los poderes locales. La demostración de la imposibilidad refuta el valor alegado para la propuesta política en la medida en que se prueba la imposibilidad.

Desde dentro, ciertas acciones pueden tenerse científicamente como no éticas porque violan determinados requerimientos básicos basados en elementos indiscutibles del sentir y el pensar humanos. Bajo determinadas circunstancias la naturaleza humana no puede escapar del sentimiento de repulsa hacia ciertas acciones, y en sentido contrario, tampoco puede escapar del sentimiento de aprobación hacia otras. Es verdad que la mayoría de los sentimientos que se alegan como universales no son sino sentimientos limitados a ciertos individuos o grupos; otros, pese a ser bastante universales, no lo son del todo. Pero existen sentimientos que son tan universales que nunca se ha observado excepción alguna e incluso sería imposible llegar a imaginarnos alguna excepción. Por ejemplo, parece que el sentimiento de justicia e injusticia está indiscutiblemente presente en el sentir humano. Pese a que las opiniones sobre lo que es justo o no difieren considerablemente, la interconexión entre justicia y verdad parece ser uno de los elementos universales e invariables en el sentir humano. No puede no sentirse que es injusto que alguien, a sabiendas, haga una afirmación discriminatoria falsa sobre otra persona, o si sabiendo que es inocente, la castigue por lo que otro ha hecho.

Otro elemento necesario en el sentir humano es que lo que es igual de acuerdo con un sistema de valores aceptado debe ser tratado igual. Tomando el ejemplo anterior, el castigo se considerará inevitablemente injusto si ha sido imposible para la persona castigada hacer lo que se esperaba que hiciera.

A raíz de lo anterior, podemos decir que las afirmaciones sobre elementos universales no derivan de definiciones arbitrarias de justicia, sino que pueden derivarse de sentimientos necesarios connaturales al ser humano. Investigar si esto se produce es algo accesible a la investigación científica. Y si estos elementos se consideran en su conjunto y se combinan con los 
dos métodos propuestos por los relativistas — la clarificación del sentido de las interpretaciones propuestas y el análisis de sus implicaciones- los elementos demostrables que se obtienen son de considerable importancia. Especialmente, la exigencia de verdad en la justicia tiene gravísimas consecuencias, objetiva y subjetivamente hablando, ya que muchos malos políticos se han basado en falsedades para justificar sus decisiones y acciones. Respecto a la categoría de la imposibilidad, los ejemplos aquí propuestos dan muestra de su importancia.

\section{IV. ¿EXISTE LA JUSTICIA OBJETIVA?}

La tercera pregunta que nos hacemos siguiendo el esquema de nuestro alegato contra el relativismo absoluto de los valores es la siguiente: ¿qué es justo y qué es injusto? En principio, parece que los postulados de justicia no pueden considerarse independientemente del sistema de valores aceptado en un determinado momento histórico y lugar por una persona o grupo de personas. Estos postulados variarán especialmente si consideramos al individuo como valor superior al grupo o viceversa. Si, como mantienen los relativistas, los valores últimos no pueden probarse, el análisis científico sólo puede sustentarse en los diferentes sistemas de valores aclarando su verdadero sentido y significado, y señalando las consecuencias a las que llevaría la aplicación de determinados postulados de justicia. De esta manera, la elección entre los valores más elevados no sería una cuestión que pudiera resolver la ciencia o la justicia, sino que sería a la propia creencia a la que correspondería tal elección como un a priori de la justicia. Esta afirmación, que abandona todo estándar universal, absoluto e inmutable de justicia, parece asestar un golpe mortal a cualquier consideración sobre una ley natural en la que se ha basado la filosofía desde hace más de dos mil años. Pero, si la justicia realmente es tan relativa, ¿cómo puede nadie clamar por ella? La realidad demuestra que todavía no se han abandonado los intentos por superar el relativismo y describir no una ni varias ideas de justicia, sino la idea universal de justicia. Se trata de encontrar principios esenciales que puedan proponerse como principios absolutos u objetivos de justicia con certeza científica o evidencia metafísica. Sin embargo, en la práctica, muchos de estos principios no se han reconocido ni siquiera en los países llamados civilizados e incluso han entrado en contradicción en los diferentes sistemas políticos: no sólo hemos perdido la ley natural sino también el acuerdo 
práctico sobre cuáles son los valores más elevados. En este sentido, creo que podemos seguir afirmando con Roscou Pound que «necesitamos una medida sobre los valores con la que podamos trabajar, sobre la que juristas de diferentes puntos de vista filosóficos y diversas corrientes sociológicas puedan estar de acuerdo» ${ }^{7}$.

No se trata sólo de que existan varias ideas de justicia en diferentes individuos cuya validez o invalidez no se pueda demostrar. Incluso cada individuo es capaz de tener varias ideas de justicia de forma que nuestras ideas y sentimientos acerca de la justicia pueden ser duales según el sistema de valores al que nos atengamos en cada momento e incluso simultáneamente. En concreto, existen dos niveles diferentes en nuestras ideas de justicia y los dos dependen de algo exterior a la esfera de la propia justicia: o bien pensamos en la justicia en consideración a las instituciones presentes o bien trascendemos dichas instituciones ${ }^{8}$. La primera -a la que Arnold Brecht denomina la idea tradicional de justicia- acepta las instituciones fundamentales que constituyen la base de nuestra vida social diaria dándolas por hecho, sin cuestionarlas. La segunda - llamada por Brecht idea transtradicional de justicia - toma distancia de estas instituciones y las critica de acuerdo con principios tomados de un esquema interpretativo transtradicional. Tanto en uno como en otro caso se pueden distinguir algunos elementos que no son relativos en la idea o sentimiento mismos de justicia; es decir, parece que existen elementos comunes a todas las ideas y a todos los sentimientos de justicia. El profesor Brecht desarrolla esta tesis uniéndose a las propuestas que apuntó Francis Wilson y que hemos señalado más arriba. En este sentido, Brecht afirma que hay cuatro indicaciones a primera vista que apoyan la asunción de que todas las ideas de justicia tienen algo en común y son las siguientes: primero, dichas ideas existen en todas partes como una categoría específica de ideas; segundo, el término justicia o su equivalente aproximado existe en todas partes; tercero, el deseo humano de justicia es un factor tan universal que nadie en la vida pública puede renunciar a presentar sus actos como justos, y cuarto, existe una indicación negativa que nos permite constatar fácilmente que un acto es injusto bajo cualquier punto de vista.

${ }^{7}$ R. Pound, «Fifty years of Jurisprudence», Harvard Law Review, vol. 51 (1938), p. 460.

${ }^{8}$ Véase A. BRECHT, «Relative and Absolute Justice», Social Political Research, vol. 6 (1939), pp. 64 y ss. 


\section{ELEMENTOS UNIVERSALES PRESENTES EN TODA IDEA DE JUSTICIA}

Partiendo de lo anterior, podemos decir que el término universal de justicia responde a una necesidad humana universal de expresar no sólo su acuerdo con las leyes existentes, sino también su crítica a las mismas por ser injustas. Esta necesidad universal de expresión se refiere a algo que, por lo menos, tiene algunos elementos en común en todas partes y en todos los tiempos. No podemos dudar de lo importante que estos elementos son para la naturaleza humana si nos fijamos en la verdadera pasión que levantan y siempre han levantado.

Arnold Brecht, en sintonía con Wilson, recoge y amplía los elementos comunes a toda idea de justicia, sea cual sea la creencia individual ${ }^{9}$. Son elementos universales en sentido empírico y absolutos en el sentido de que son postulados invariables de justicia en todos los sistemas de valores existentes. Brecht recoge cinco de estos postulados — siendo el de mayor importancia y la base del resto el primero de ellos- que exponemos a continuación.

En sentido objetivo la justicia, como ya hemos señalado, exige acuerdo con la verdad. En sentido subjetivo, la justicia exige acuerdo con lo que pensamos que es verdad. El postulado de la verdad tiene implicaciones importantes tanto para los hechos de un caso concreto como para las consecuencias que se derivan de él. Cualquier afirmación indiscrimina$\mathrm{da}$, como, por ejemplo, que alguien ha robado, es perfectamente justa si se atiene a la verdad. Esto es aplicable no sólo a cualquier tipo de juicio moral o legal, sino también a los juicios sobre las aptitudes y los logros; cualquiera que fueran los méritos o deméritos de Napoleón, Hitler, Lennin, los judíos, los hutus, los tutsi, los saharauis, todos ellos han reclamado la verdad en el juicio final sobre ellos. Este reclamo no puede negársele ni siquiera a Judas Iscariote. Además, incluso si alguien pensara que el acto de mentir tiene un valor, su propio vocabulario interno no podría llamar verdad a lo que es mentira ni justo a lo que es contrario a la verdad. Nadie puede negar que su sentido de la justicia, sus ideas respecto a ella, requiere la verdad como base y parte de la justicia. Y esto es cierto aunque el hombre construya permanentemente sistemas y argumentos basados en mentiras e ilusiones. Este impulso del ser humano hacia la falsedad es un hecho

\footnotetext{
9 A. BRECHT, «Relative and Absolute Justice», op. cit., p.75.
} 
constatable y penetra hondamente en el reino de la justicia de tal forma que los peores crímenes contra la verdad y la justicia se han cometido y se cometen en su nombre. Las personas nos mentimos a nosotros mismos y a los otros en nuestras creencias de que algo es verdad y, por tanto, justo. En sentido contrario, el hecho de que se proclame la justicia de una causa, incluso cuando los hechos son deliberadamente distorsionados, siempre se asocia a que los hechos alegados son ciertos o por lo menos que se piensa que son verdad. Lo expuesto prueba que existe una conexión inseparable entre las ideas de justicia y verdad. La idea de que un juicio sólo es objetivamente justo cuando se basa en la verdad siempre ha existido, de manera que el postulado de la verdad ataca la base misma del relativismo y lo hace de diferentes maneras.

En primer lugar, podemos observar que la mayoría de las interpretaciones sobre valores se basan en asunciones sobre hechos y que estas asunciones básicas se pueden probar como inciertas si lo son. En segundo lugar, puede probarse que la interpretación está basada en un pensamiento pobre que puede corregirse por otro más profundo y reflexivo. También puede probarse, en tercer lugar, que los sacrificios necesarios para conseguir ciertos valores y los riesgos implícitos que se corren son mayores de lo esperado. Finalmente, puede probarse que las consecuencias de atenerse a los valores aceptados son diferentes de las que se habían asumido. Además, no se puede negar que la idea misma de justicia exige verdad en el sentido de que nos obliga a elegir de acuerdo con nuestras convicciones o creencias. Siempre que la verdad nos convence no podemos dejar de seguirla en nuestras ideas transtradicionales de justicia. Y si llegamos a ver que nuestras convicciones y creencias se basaban en errores sobre los hechos, o en un pensamiento superficial, las asunciones que hemos realizado irán rompiéndose poco a poco hasta cambiar nuestras propias convicciones. Esta aplicación de la ciencia al análisis de los valores y en su lucha por la verdad modifica, no pocas veces, las interpretaciones que realizamos, así como las ideas y sentimientos que tenemos sobre la justicia. La ciencia hoy puede ayudarnos, con sus métodos interpretativos y de análisis de las consecuencias, a determinar la justicia o injusticia de decisiones éticas y políticas relativas a temas como el aborto, la pena de muerte, la eutanasia, la aprobación de una legislación que facilite al máximo los trámites del divorcio (sobre todo en los relativo a las consecuencias derivadas para los hijos, si los hubiere), la adopción de hijos por parte de personas homosexuales y un largo etcétera de problemas sin resolver que acucian a la sociedad del siglo XXI. 
Junto al postulado de la verdad, la justicia exige la generalidad del sistema de valores aplicado, de forma que es injusto, y así puede probarse, utilizar arbitrariamente diferentes sistemas de valores en casos semejantes. De este postulado se derivan otros dos que nos obligan, en aras a la justicia, a tratar igual lo que es igual según el sistema de valores aceptado, y a no restringir la libertad más allá de los requerimientos del sistema de valores aceptado. El último postulado de justicia que el profesor Brecht propone como universal se presenta de modo independiente y se refiere a los límites impuestos por la propia naturaleza, de modo que es injusto castigar por no cumplir una ley o una orden de imposible cumplimiento. Puede que existan diferentes opiniones subjetivas de lo que es y lo que no es posible realizarse; el receptor de la orden puede diferir de la opinión de quien debe obedecerla y, en este caso, el receptor creerá que le están tratando injustamente. Ésta es la manera en la que surgen los rebeldes por una causa de justicia en los casos en los que no se pretende lograr una jerarquía de valores, sino remediar lo que se considera un acto o una orden injusta por ser imposible su cumplimiento.

Estamos de acuerdo con el profesor Brecht en que, sumando los cinco postulados propuestos, podemos obtener una mínima definición de justicia que sería la descripción exacta de un fenómeno, de una forma universal del pensar y el sentir humanos, basada en características universales de la existencia humana. Es la suma de todos ellos y su interrelación lo que les da un significado pleno. Sea cual sea este significado, la ciencia tiene la obligación de trabajar por establecer con objetividad lo que realmente es relativo-variable y lo que es absoluto-invariable en la justicia. Esto es de especial importancia en el campo de la política, puesto que los políticos tienen como fin primordial la realización de la justicia.

\section{BIBLIOGRAFÍA}

Brecht, A., «Relative and Absolute Justice», Social Political Research, vol. 6 (1939).

— «The Rise of Relativism in Political and Legal Philosophy», Social Political Research, vol. 6 (1939).

— «The Search for Absolutes in Political and Legal Philosophy», Social Political Research, vol. 7 (1940).

- «Beyond Relativism in Political Theory», American Political Science Review, vol. XLI, núm. 3 (1947). 
— «The Myth of Is and Ought», Harvard Law Review, vol. 54, núm. 5, Cambridge, Massachussets, 1941.

Werthlermer, M., «Some problems in the theory of ethics», Social Political Research, vol. 2 (1935).

Pound, R., «Fifty years of Jurisprudence», Harvard Law Review, vol. 51 (1938).

Schmidt, P. F., «Some criticism of cultural relativism», Journal of Philosophy, vol. 52 (1955).

Déntrevès, A. P., «The case of Natural Law reexamined», Natural Law Forum, 1956.

LECLERCQ, J., «Suggestions for clarifying Natural Law», Natural Law Forum, vol. 3 (1958).

Messner, J., «The postwar natural law revival and its outcome», Natural Law Forum, vol. 4 (1959). 